\title{
Associations Between Parental Media Monitoring, Media Use, and Internalizing Symptoms During Adolescence
}

Laura M. Padilla-Walker

Brigham Young University, laura_walker@byu.edu

Laura A. Stockdale

Ryan D. McLean

Follow this and additional works at: https://scholarsarchive.byu.edu/facpub

Part of the Social and Behavioral Sciences Commons

\section{Original Publication Citation}

Padilla-Walker, L. M., Stockdale, L., \& *McLean, R. (2020). Associations between parental media monitoring, media use, and internalizing symptoms during adolescence. Psychology of Popular Media Culture, 9, 481-492.

\section{BYU ScholarsArchive Citation}

Padilla-Walker, Laura M.; Stockdale, Laura A.; and McLean, Ryan D., "Associations Between Parental Media Monitoring, Media Use, and Internalizing Symptoms During Adolescence" (2019). Faculty Publications. 5505.

https://scholarsarchive.byu.edu/facpub/5505

This Peer-Reviewed Article is brought to you for free and open access by BYU ScholarsArchive. It has been accepted for inclusion in Faculty Publications by an authorized administrator of BYU ScholarsArchive. For more information, please contact ellen_amatangelo@byu.edu. 


\title{
Associations Between Parental Media Monitoring, Media Use, and Internalizing Symptoms During Adolescence
}

\author{
Laura M. Padilla-Walker, Laura A. Stockdale, and Ryan D. McLean \\ Brigham Young University
}

\begin{abstract}
Although time spent using media has been linked to internalizing problems, few studies have explored the role that parents might play in these associations. The current study explored how controlling and autonomy-supportive restrictive and active parental media monitoring were associated with adolescents' internalizing problems via time spent using media (media multitasking, social media, TV, video games, music, reading, texting, and Internet). The current study used data from a national study of teens aged 10-20 ( $N=1,193,52 \%$ female, $68 \%$ White, $13 \%$ Black, $11 \%$ Latino). Results suggested that only autonomy-supportive restrictive media monitoring was associated with lower media use for both boys and girls on all platforms of media except reading. In turn, media multitasking was associated with higher levels of anxiety and depression, and social media use was associated with higher levels of anxiety. There were also a number of associations that varied as a function of adolescent sex. Discussion focuses on the links between parental media monitoring, media use, and adolescents' internalizing symptoms.
\end{abstract}

\section{Public Policy Relevance Statement}

Media use and mental health were lower for teens when parents used autonomy-supportive restrictive monitoring of adolescents' media, supporting the notion that teens benefit when parents have restrictions on media that maximizes adolescents' autonomy. It is also of note that media multitasking, social media use, and video game use (for boys) were associated with higher levels of internalizing symptoms, whereas TV use and texting (for boys) were associated with lower symptoms. This suggests not all platforms are associated with the same outcomes, and that associations may vary for boys and girls.

Keywords: parental media monitoring, parental mediation, media, internalizing, adolescents

Supplemental materials: http://dx.doi.org/10.1037/ppm0000256.supp

Depression and anxiety are among the leading internalizing behavior diagnoses for adolescents and a major concern for parents and health professionals (National Institute of Mental Health [NIMH], 2016; Weinberger et al., 2018), in part because of their relation to negative outcomes such as lower sleep quality (Palmer, Oosterhoff, Bower, Kaplow, \& Alfano, 2018), suicidal ideation (World Health Organization, 2018), addiction (Brenhouse, Sonntag, \& Andersen, 2008; Kelley, Schochet, \& Landry, 2004; Lai et al., 2015), and substance abuse (Hussong, Jones, Stein, Baucom, \& Boeding, 2011; Pardini, Lochman, \& Wells, 2004). Previous researchers have shown that adolescence is a developmental risk period for the presentation and exacerbation of internalizing behaviors (Hayward \& Sanborn, 2002). Researchers have theorized that this increased risk during adolescence may be due to

This article was published Online First August 29, 2019

(D) Laura M. Padilla-Walker, Laura A. Stockdale, and Ryan D. McLean, School of Family Life, Brigham Young University.

Correspondence concerning this article should be addressed to Laura M. Padilla-Walker, School of Family Life, Brigham Young University, 2071 JFSB, Provo, UT 84602. E-mail: laura_walker@byu.edu a variety of factors including biological changes associated with the onset of puberty (Natsuaki et al., 2009), increased stress, perhaps due to increased autonomy (Graber \& Sontag, 2009), a decline in positive affect (likely due to biological changes; Weinstein, Mermelstein, Hankin, Hedeker, \& Flay, 2007), and increased cognitive skills which allow for rumination on negative and stressful events (Avenevoli \& Steinberg, 2001).

Factors contributing to depressive symptomology are multifaceted, but research has suggested higher levels of internalizing behaviors are associated with media use (Houghton et al., 2018; Maras et al., 2015; Twenge, Joiner, Rogers, \& Martin, 2018). These findings are especially relevant because over $95 \%$ of American teenagers (age 13-18) have, or have access to, a smartphone (Anderson \& Jiang, 2018) and are spending nearly $9 \mathrm{hr}$ a day on entertainment media (i.e., media outside of school and homework; Rideout, 2016). In conjunction with the rise in new media, research has also shown an increase in media-multitasking (engaging in multiple forms of media at once; van der Schuur, Baumgartner, Sumter, \& Valkenburg, 2015). Although these results are somewhat disheartening, research has found that parental monitoring of their child's media may be an effective way to attenuate the potentially negative effects of media use (Nathanson \& Cantor, 
2000). Thus, the purpose of the current study was to better understand the role of parental media monitoring on adolescents' internalizing behavior via reduced time spent with media (including multitasking) using a cross-sectional national sample of adolescents, aged 10-20.

\section{Media Use and Internalizing Behavior}

Media use has been associated with higher levels of internalizing symptomology during adolescence, which may be partially explained by the media practice model (Steele \& Brown, 1995). The media practice model addresses the intentions of individuals in selecting media, the ways in which individuals interact with media, and the ways in which individuals apply media to their lives. Media selection may occur because of biological or environmental factors, or simply out of convenience. Media interaction is the way that an individual interacts with media and interprets various messages. Media application is the way that the media messages are internalized and applied in day-to-day interactions. The media practice model gives us insights into why media may be associated with internalizing problems, and raises issues of direction of effects. For example, the notion of media selection may suggest that adolescents with internalizing symptomology select certain types of media as a means to cope with a negative emotional state. On the other hand, interaction with negative or isolating media may lead to increased levels of internalizing symptoms (Marino et al., 2016; Rubin, 1994; Spada, Langston, Nikčević, \& Moneta, 2008), especially if harmful media messages are applied and internalized. Previous researchers have theoretically argued that it is not media use itself that is causing adolescents' internalizing symptoms, but rather factors related to the content of the media and adolescents' reasons for using the media (Marino et al., 2016; Rubin, 1994; Spada et al., 2008). Taken together, this theoretical model and empirical research suggest that the link between media use and adolescents' internalizing symptomology is likely bidirectional.

Previous cross-sectional research has shown that adolescents (aged 14-18) who spent more time on new media reported higher levels of internalizing problems (Twenge et al., 2018), and another study found that Internet use specifically was associated with depression and suicidal ideation between ages 13 and 18 (Do, Shin, Bautista, \& Foo, 2013). Although both of these studies have established a link between media use and depressive symptomology, other studies have not found links when looking at more severe forms of depression (Jelenchick, Eickhoff, \& Moreno, 2013). Longitudinal research adds to these findings by suggesting that higher levels of screen time, mobile phone use, and TV viewing (Bickham, Hswen, \& Rich, 2015; Houghton et al., 2018), as well as high levels of social media use (Nesi, Miller, \& Prinstein, 2017), were associated with higher levels of internalizing problems over time. Though these studies suggest media use may be impacting internalizing problems, other research has found a longitudinal link suggesting young adolescents seek media to help cope with negative emotional states (Eschenbeck, Schmid, Schröder, Wasserfall, \& Kohlmann, 2018). Taken together, theory and growing empirical evidence suggest that media may play a role in the development of internalizing problems during adolescence, but directionality, if it exists, is difficult to measure. That being said, there seems to be theoretical and empirical evidence to suggest that media use is associated to internalizing problems to some degree.

To further complicate these associations, because media has become so complex and multifaceted, a more nuanced approach may be beneficial. Adolescents' lives today are saturated with media. Research typically struggles to keep up with the latest technology and is often behind what adolescents are using in terms of media and media content. Rather than focusing on one form of media, in their digitally immersive reality, it is important to focus on a variety of media to gain a clearer perspective on the influences of media in adolescents' lives. As examples of the variety of media associated with adolescent internalizing behaviors, research has found longitudinal links between social media use (Coyne, Padilla-Walker, Holmgren, \& Stockdale, 2018; Nesi et al., 2017), TV (Bickham et al., 2015), texting (Coyne, Padilla-Walker, \& Holmgren, 2018) and internalizing behaviors, but it is important to mention that another team of researchers found cross-sectional links that were no longer significant in longitudinal analyses (Houghton et al., 2018). In cross-sectional research, higher rates of internalizing symptoms have been associated with TV viewing (Barcaccia et al., 2017; Domingues-Montanari, 2017), video games (Gentile et al., 2011; Holtz \& Appel, 2011), and social media use (Primack et al., 2017; Woods \& Scott, 2016) compared with other platforms of media, suggesting that some types of media might be associated with internalizing, whereas others may not.

A growing body of research also suggests a link between media multitasking (Becker, Alzahabi, \& Hopwood, 2013), such as listening to music while playing a video game or texting while watching a movie, and depression in college students, even after controlling for overall media use (Reinecke et al., 2017). Several theories have been presented as to why media multitasking may be particularly detrimental to behavioral outcomes. These theories generally fall into two categories: displacement and decreased cognitive resources. Researchers have argued that media multitasking may lead to increased time with the media and, as a result, may displace activities and interactions related to positive outcomes (Reinecke et al., 2017). Researchers have also argued that media multitasking leads to decreased cognitive resources being allocated to each activity, and as a result, the quality of interactions and behavior decreases (Becker et al., 2013). The decrease in quality of interactions as a result of media multitasking (Ophir, Nass, \& Wagner, 2009), and the decreased attention and cognitive resources given to interactions and behavior as a result of media multitasking (Baumgartner, Weeda, van der Heijden, \& Huizinga, 2014), may place teens at increased risk for poorer social relationships and internalizing symptoms (Alzahabi \& Becker, 2013). Thus, in the current study we explored traditional media (e.g., TV, reading, music), new media (e.g., social media, Internet, video games, texting), and media multitasking as they related to adolescents' internalizing symptoms.

\section{Parental Media Monitoring and Internalizing Behavior Via Adolescent Media Use}

Research has shown that parental media monitoring can be effective at reducing negative effects of media (Nathanson \& Cantor, 2000). Parental monitoring usually involves either parentchild media-based conversations about media content ("active monitoring") or restrictions surrounding the amount of screen time 
("restrictive monitoring"; Gentile, Reimer, Nathanson, Walsh, \& Eisenmann, 2014), media platform (Padilla-Walker, Coyne, Kroff, \& Memmott-Elison, 2018), and/or content that the child is allowed to view (Gentile, Nathanson, Rasmussen, Reimer, \& Walsh, 2012; Nathanson, 1999). Restrictive monitoring has been associated with less screen time (Collier et al., 2016) and more reading time (Gentile et al., 2014), but higher levels of internalizing behavior in preadolescence (Fardouly, Magson, Johnco, Oar, \& Rapee, 2018) and longitudinally in early adolescence (Bickham et al., 2015). It is typically viewed as less adaptive than active monitoring in later adolescence because of the adolescent's need for higher levels of autonomy (Padilla-Walker, Coyne, \& Collier, 2016) and more mature cognitive processes. Active monitoring can be more effective at promoting developmentally appropriate autonomy because, using this strategy, the parent ideally engages their child in conversations about media themes, characters, and content that promote critical thinking about the differences between the on-screen world and the real world (Nathanson \& Cantor, 2000; Padilla Walker et al., 2018).

However, recent findings have suggested the type of media monitoring may not be as important as the style in which the monitoring is implemented. These findings posit that individuals will react more favorably to an autonomy-supportive parenting style whether it is classified as active or restrictive media monitoring (Fikkers, Piotrowski, \& Valkenburg, 2017). Autonomysupportive restrictive media monitoring may be when a parent places limits on their child's media use, but also takes the time to explain why the rule is important and engage the child's feedback in setting rules and limits. Autonomy-supportive active media monitoring may be when parents discuss with their child that media is not reflective of real life and may distort perspectives with the goal of promoting critical thinking rather than forbidding the child to use media.

Self-determination theory suggests that basic human psychological needs include autonomy, relatedness, and competence (Deci \& Ryan, 2012), and given that adolescents have an increased need for autonomy, parenting that infringes on adolescent autonomy is likely to undermine the parent-child relationship and adolescents' mental health (Soenens, Vansteenkiste, \& Beyers, 2019). Thus, a controlling media monitoring style impedes upon an individual's volitional actions through regulations and leaves the responsibility for deciding upon proper media in the hands of the parent, which likely leaves the adolescent feeling less competent. For example, even active media monitoring could be controlling if a parent lectured about why media was potentially harmful and then became angry if the child did not comply. On the other hand, autonomy-supportive media monitoring (whether active or restrictive in type) allows the parent to guide the adolescent in thinking critically about media influences in his or her life through discussions that transfer the responsibility to the adolescent and promote well-being and self-generated behavior. Given a significant body of research suggesting that inappropriate parental control is associated with adolescents' internalizing problems (Soenens, Luyckx, Vansteenkiste, Duriez, \& Goossens, 2008; Werner, der Graaff, Meeus, \& Branje, 2016), we thought it likely that controlling approaches to parental media monitoring would also be a risk factor for adolescents' anxiety and depression. One possible mechanism for the link between autonomy-supportive parenting and greater mental health for adolescents may be time spent using media. When an adolescent takes charge of her media consumption, she is better able to engage in critical thinking and learn to make decisions about media use based on internalized values, rather than on external control from the parent (Valkenburg, Piotrowski, Hermanns, \& de Leeuw, 2013).

\section{Current Study}

The current study sought to explore the cross-sectional links between parental media monitoring and adolescents' internalizing symptoms via adolescents' media multitasking and media use. Thus, we propose the following hypotheses:

Hypothesis 1: Given existing theory and research (Deci \& Ryan, 2012; Soenens et al., 2008; Werner et al., 2016), we hypothesized that autonomy-supportive media monitoring styles (both active and restrictive) would be associated with lower levels of adolescent internalizing problems, and that controlling media monitoring styles would be associated with higher levels of internalizing problems.

Hypothesis 2: Given that active monitoring promotes critical thinking and being an active consumer of media (Nathanson \& Cantor, 2000; Padilla-Walker et al., 2018), and restrictive monitoring promotes less time spent with media (Collier et al., 2016), we hypothesized that both autonomy-supportive restrictive and active monitoring would be associated with less time spent with media.

Hypothesis 3: Based on the media practice model (Steele \& Brown, 1995) and empirical research that has found longitudinal links between media use and adolescents' internalizing symptoms (Bickham et al., 2015; Houghton et al., 2018; Nesi et al., 2017), we hypothesized that higher levels of media use would be associated with internalizing problems, but explored how these relations might vary as a function of the type of media used.

Hypothesis 4: Finally, we explored the indirect effects of parental media monitoring on adolescents' internalizing problems via media use, and hypothesized that media monitoring would be associated with lower levels of internalizing problems via lower levels of media use.

Furthermore, there are mean differences in both media use and internalizing behavior as a function of adolescent sex, age, and family income (Altemus, Sarvaiya, \& Neill Epperson, 2014; Breslau et al., 2017; Rideout, 2016). In addition to these mean differences, research has been mixed with some suggesting that parental media monitoring might impact girls differently than boys (Coyne, Padilla-Walker, Stockdale, \& Day, 2011) because of the different expectations male and female children have of how parents will be involved with the different types of media they use. Thus, we thought it important to consider how the relations in the current study might be different for boys and girls. Research also suggests that parenting may be differentially associated with positive outcomes for early compared with late adolescents (Nathanson, 1999; Padilla-Walker et al., 2016). Indeed, theories of parenting and child development suggest that as children age and desire more autonomy, parenting that may have seemed appropriate to children feels controlling to teenagers (Deci \& Ryan, 2012), suggesting the 
need to consider the effectiveness of parental media monitoring at different ages. Therefore, although we had no specific hypotheses in this regard, we posed the following research question:

Research Question 1: Are relations between parental media monitoring, media, and internalizing problems moderated by adolescent age and sex?

\section{Method}

\section{Participants and Procedure}

Participants were taken from a national quota sample of teenagers who participated in an online survey examining adolescent media use. The current study consisted of 1,155 adolescents aged 10-20 (51\% female), with 315 early adolescents (aged 10-12), 315 middle adolescents (aged 13-15), and 525 late adolescents (aged 16+). Researchers have found that quota samples generally result in comparable results to probability-based samples (Cumming, 1990; Pew Research Center, 2016). Ethnicity was 69\% European American, 13\% African American, 11\% Hispanic, and 5\% Asian American. Average household income was between $\$ 35$ and $\$ 49,000$, with $30 \%$ of the sample making less than $\$ 35,000$ annually and only just over $10 \%$ making more than $\$ 100,000$ annually.

After obtaining institutional review board approval from the sponsoring university, participants were recruited via Qualtrics (a research firm that collects data for researcher, private, and public corporations) from an online panel of participants across the United States who had previously agreed to participate in research. Participants were given a brief online survey that took less than 20 min to complete, and were compensated on a sliding scale in points (which are accumulated to receive goods or credits to places such as iTunes, Amazon, etc., gift cards, or cash). There were very few instances of missing data, but they were dealt with using full information maximum likelihood.

\section{Measures}

Media monitoring. Adolescents responded to a 12-item adapted measure of media monitoring taken from the Perceived Parental Media Monitoring Scale (Valkenburg et al., 2013). The measure was adapted for the current study in an attempt to make it shorter for the online survey format. Adolescents were presented four main items: two that were representative of restrictive monitoring and two active monitoring (e.g., "How often do your parents tell you that you are not allowed to play video/computer games because they are meant for older kids?" and "How often do your parents tell you that what you see in movies and commercials is different than real life?") Items were answered on a 5-point Likert scale from 1 (never) to 5 (very often). Directly after each main item, adolescents were presented with follow-up items to identify how their parents monitor their media use, including a prompt of, "And if your parents would tell you this, how would they do this?" Items were designed to assess if parents were attempting to control adolescents' media use and exposure or give information and support while encouraging adolescents' autonomy regarding media. Two controlling items $(r=.16-.47, p<.001$, e.g., "They would ... get angry if I still want to play those games.") and two autonomy-supportive items ( $r=.21-.65, p<$ .001 , e.g., "They would . . . explain to me why it's better to not play those games.") were included for both restrictive and active monitoring on a 5-point Likert scale from 1 (not at all true) to 5 (completely true). We took the average of the two items in each category, which resulted in four scales (Controlling Restrictive and Active Monitoring, and Autonomy-Supportive Restrictive and Active Monitoring), with higher scores indicative of higher levels of parental monitoring. A confirmatory factor analysis was conducted to determine that the factor structure of the shortened scale matched that of the full scale (Valkenburg et al., 2013), and four factors were confirmed, each with two items loading $>.50$.

Media use. Adolescents' time spent using a variety of platforms of media was assessed using eight items (Stockdale, Coyne, $\&$ Padilla-Walker, 2018). The stem of each question was "How much time do you spend on the following media activities on a typical day," and adolescents responded to watching TV programs, playing video games, listening to music, reading magazines or books, spending time on the Internet (not doing any of the other activities listed above), social media, and texting on a cell phone on an scale of 1 (none), 2 (less than $30 \mathrm{~min}), 3$ (31-60 min), 4 (1-2 $h r), 5(2-3 h r), 6(3-4 h r), 7(5-6 h r), 8(7-8 h r)$, and 9 (9 or more hours). Adolescents also answered one question about media multitasking (Baumgartner et al., 2014; "While using any type of media (watching TV, listening to music, talking/texting on the phone, etc.) how often do you do other activities involving the media?") on a scale of 1 (never) to 4 (very often).

Internalizing problems. Adolescents reported on their own anxiety using three items from the Spence Children's Anxiety Scale (Spence, 1998; $\alpha=.81$ ), which has been used extensively with this age-group. Participants answered on a 4-point Likert-type scale from 1 (not at all) to 4 (a lot), with higher scores indicating higher levels of anxiety. Example items include "When I have a problem my heart beats really fast" and "I worry that something bad will happen to me."

Depression was measured using three items from the Center for Epidemiological Studies Depression Scale for Children $(\alpha=.88$; Faulstich, Carey, Ruggiero, Enyart, \& Gresham, 1986), which has been used extensively with this age-group. Participants were asked to indicate how true several statements were of themselves for the past week. Responses ranged on a 4-point Likert-type scale from 1 (not at all) to 4 (a lot), with higher scores indicating greater depressive symptoms. Example items include "I wasn't able to feel happy, even when my family or friends tried to make me feel better" and "It was hard to get started doing things."

\section{Results}

\section{Descriptive Statistics and Correlations}

Data were explored for univariate and multivariate outliers, and none were identified. Means, standard deviations, and correlations between all study variables are in Table 1 . It is of note that parental media monitoring was differentially and not consistently associated with media use, but overall restrictive approaches were associated with lower levels of media use, and active approaches with higher levels. In addition, controlling approaches to media monitoring were associated with higher levels of internalizing problems, and autonomy-supportive approaches to lower levels. Media 
Table 1

Descriptive Statistics and Correlations for Continuous Study Variables

\begin{tabular}{|c|c|c|c|c|c|c|c|c|c|c|c|c|c|c|c|c|}
\hline Variable & 1 & 2 & 3 & 4 & 5 & 6 & 7 & 8 & 9 & 10 & 11 & 12 & 13 & 14 & 15 & 16 \\
\hline 1. Age & - & & & & & & & & & & & & & & & \\
\hline 2. Income & $-.64^{* *}$ & - & & & & & & & & & & & & & & \\
\hline 3. Controlling restrictive & $-.09^{* *}$ & $.09^{* * *}$ & - & & & & & & & & & & & & & \\
\hline 4. Controlling active & $.14^{* * *}$ & $-.10^{\text {*** }}$ & $.28^{* * *}$ & - & & & & & & & & & & & & \\
\hline $\begin{array}{l}\text { 5. Autonomy-supportive } \\
\text { restrictive }\end{array}$ & $-.31^{* * *}$ & $.23^{\text {*** }}$ & $.22^{* * *}$ & $-.08^{*}$ & - & & & & & & & & & & & \\
\hline 6. Autonomy-supportive active & $-.23^{* *}$ & $.23^{* * *}$ & $-.08^{*}$ & $-.47^{* * *}$ & $.34^{* * *}$ & - & & & & & & & & & & \\
\hline 7. Media multitasking & $.25^{* * *}$ & $-.13^{* *}$ & .05 & $.15^{* *}$ & -.07 & $.10^{* * *}$ & - & & & & & & & & & \\
\hline 8. Social media & $.15^{* *}$ & $-.07^{*}$ & $.09^{*}$ & $.11^{* * *}$ & -.07 & -.02 & $.24^{* *}$ & - & & & & & & & & \\
\hline 9. TV & .04 & -.04 & $.10^{* * *}$ & .02 & -.05 & $.10^{* *}$ & $.07^{*}$ & $.29^{* * *}$ & - & & & & & & & \\
\hline 10. Video games & .04 & -.04 & .01 & $.09^{* * *}$ & -.06 & .04 & .05 & $.15^{\text {** }}$ & $.34^{* *}$ & - & & & & & & \\
\hline 11. Music & $.32^{* * *}$ & $-.22^{* * *}$ & .01 & $.11^{* *}$ & $-.16^{* *}$ & -.05 & $.24^{* *}$ & $45^{* *}$ & $26^{* *}$ & $.33^{* *}$ & - & & & & & \\
\hline 12. Reading & .03 & .00 & .02 & .05 & .03 & $.07^{*}$ & .05 & $.16^{* * *}$ & $.29^{* * *}$ & $.24^{* *}$ & $.31^{* * *}$ & - & & & & \\
\hline 13. Texting & $.10^{\text {** }}$ & -.01 & .05 & $.07^{*}$ & $-.09^{*}$ & .00 & $.21^{* *}$ & $.53^{* *}$ & $.30^{* *}$ & $.13^{* *}$ & $.39^{\text {*** }}$ & $.11^{* * *}$ & - & & & \\
\hline 14. Internet & $.38^{* * *}$ & $-.27^{\text {*** }}$ & .02 & $.15^{* *}$ & $-.17^{* * *}$ & $-.12^{* * *}$ & $.29^{* *}$ & $.52^{* * *}$ & $27^{* * *}$ & $29^{* * *}$ & $49^{* * *}$ & $20^{* * *}$ & $.33^{* *}$ & - & & \\
\hline 15. Anxiety & $.27^{* * *}$ & $-.23^{* * *}$ & $.14^{* * *}$ & $.22^{* *}$ & $-.14^{* *}$ & $-.21^{* * *}$ & $.29^{* * *}$ & $20^{* * *}$ & -.02 & .02 & $.14^{* * *}$ & .02 & .05 & $.17^{* *}$ & - & \\
\hline 16. Depression & $.31^{* * *}$ & $-.28 * *$ & $.11^{\text {*** }}$ & $.26^{* * *}$ & $-.22^{* * *}$ & $-.27^{* * *}$ & $.27^{* * *}$ & $.15^{* * *}$ & -.02 & $.08^{* *}$ & $.21^{* * *}$ & $.06^{*}$ & .06 & $.21^{* *}$ & $.62^{\text {*** }}$ & - \\
\hline M & 15.05 & 5.41 & 3.26 & 2.86 & 3.75 & 3.88 & 2.41 & 4.19 & 4.54 & 4.10 & 4.77 & 3.04 & 4.22 & 4.79 & 2.50 & 1.82 \\
\hline$S D$ & 2.71 & 2.89 & 1.00 & 1.00 & 0.93 & 0.84 & 0.85 & 1.77 & 1.69 & 1.99 & 1.78 & 1.60 & 1.87 & 1.85 & 0.83 & 0.85 \\
\hline Range & $13-18$ & $1-10$ & $1-5$ & $1-5$ & $1-5$ & $1-5$ & $1-4$ & $1-9$ & $1-9$ & $1-9$ & $1-9$ & $1-9$ & $1-9$ & $1-9$ & $1-4$ & $1-4$ \\
\hline
\end{tabular}

multitasking, social media use, listening to music, and using the Internet were also positively associated with anxiety and depression. We conducted $t$ tests to explore sex differences on all variables and univariate analyses of variance to explore differences on all study variables as a function of the child's age (10-12 early, 13-15 middle, 16-20 late adolescence), and these results are presented in Table 2 .

\section{Associations Between Parental Media Monitoring, Media Time, and Adolescents' Depression and Anxiety}

Path analysis using structural equation modeling was explored considering parents' use of both controlling and autonomy- supportive restrictive and active parental monitoring as predictors of adolescents' time with various types of media (multitasking, social media, TV, video games, music, reading, texting, and Internet). Media use was then used to predict adolescents' depression and anxiety. All variables were represented as means and modeled as manifest variables except for depression and anxiety, which had three items each and were thus assessed using latent variables. Controls included adolescent sex $(0=$ male, $1=$ female $)$, adolescent age (continuous variable), and household income (continuous variable).

Model fit was considered acceptable with a nonsignificant $\chi^{2}$, comparative fit index $(\mathrm{CFI})>.90$, and root mean square error of

Table 2

Mean Differences in Study Variables as a Function of Adolescent Sex and Age

\begin{tabular}{|c|c|c|c|c|c|c|c|}
\hline Variable & $\begin{array}{c}\text { Male } \\
M(S D)\end{array}$ & $\begin{array}{l}\text { Female } \\
M(S D)\end{array}$ & $t$ value & $\begin{array}{c}\text { Early } \\
M(S D)\end{array}$ & $\begin{array}{l}\text { Middle } \\
M(S D)\end{array}$ & $\begin{array}{l}\text { Late } \\
M(S D)\end{array}$ & $F$ value \\
\hline 1. Age & $14.95(3.13)$ & $15.05(3.20)$ & -0.58 & - & - & - & - \\
\hline 2. Income & $4.96(3.00)$ & $4.70(3.07)$ & 1.51 & $6.58(2.32)^{\mathrm{a}}$ & $6.66(1.91)^{\mathrm{a}}$ & $3.86(3.05)^{\mathrm{b}}$ & $83.13^{\text {**** }}$ \\
\hline 3. Controlling restrictive & $3.20(0.99)$ & $3.29(1.02)$ & -1.30 & $3.44(0.95)$ & $3.27(0.98)$ & $3.18(1.03)$ & 2.64 \\
\hline 4. Controlling active & $2.80(0.97)$ & $2.79(0.99)$ & 0.16 & $2.79(1.04)^{\mathrm{ab}}$ & $2.73(0.99)^{\mathrm{a}}$ & $2.99(0.99)^{\mathrm{b}}$ & $4.27^{*}$ \\
\hline 5. Autonomy-supportive restrictive & $3.77(0.97)$ & $3.80(0.91)$ & -0.51 & $4.07(0.79)^{\mathrm{a}}$ & $3.93(0.83)^{\mathrm{a}}$ & $3.47(0.99)^{\mathrm{b}}$ & $23.38^{* * * *}$ \\
\hline 6. Autonomy-supportive active & $3.90(0.80)$ & $3.84(0.86)$ & 1.22 & $4.05(0.70)^{\mathrm{a}}$ & $4.08(0.65)^{\mathrm{a}}$ & $3.63(0.96)^{\mathrm{b}}$ & $21.41^{\text {***** }}$ \\
\hline 7. Media multitasking & $2.25(0.88)$ & $2.34(0.91)$ & -1.70 & $2.35(0.84)$ & $2.34(0.78)$ & $2.49(0.89)$ & 2.21 \\
\hline 8. Social media & $3.96(1.86)$ & $4.43(1.75)$ & $-3.98^{* * * *}$ & $3.87(1.67)$ & $4.30(1.79)$ & $4.25(1.79)$ & 2.45 \\
\hline 9. TV & $4.37(1.80)$ & $4.37(1.66)$ & 0.03 & $4.60(1.62)$ & $4.46(1.67)$ & $4.57(1.74)$ & 0.36 \\
\hline 10. Video games & $4.78(1.82)$ & $3.20(1.73)$ & $15.13^{* * * *}$ & $4.24(1.96)$ & $4.03(1.84)$ & $4.09(2.13)$ & 0.41 \\
\hline 11. Music & $4.32(1.98)$ & $4.62(1.83)$ & $-2.73^{* * *}$ & $4.33(1.53)^{\mathrm{a}}$ & $4.55(1.62)^{\mathrm{a}}$ & $5.16(1.94)^{\mathrm{b}}$ & $11.43^{* * *}$ \\
\hline 12. Reading & $2.86(1.63)$ & $2.96(1.50)$ & -1.05 & $3.00(1.59)$ & $2.96(1.57)$ & $3.12(1.64)$ & 0.625 \\
\hline 13. Texting & $3.84(1.89)$ & $4.21(1.85)$ & $-3.00^{* *}$ & $3.90(1.82)$ & $4.19(1.73)$ & $4.37(1.98)$ & 2.53 \\
\hline 14. Internet & $4.43(2.12)$ & $4.62(1.95)$ & -1.58 & $4.49(1.91)^{\mathrm{a}}$ & $4.48(1.73)^{\mathrm{a}}$ & $5.18(1.86)^{\mathrm{b}}$ & $10.10^{* * * *}$ \\
\hline 15. Anxiety & $2.36(0.82)$ & $2.58(0.85)$ & $-4.60^{* * * *}$ & $2.40(0.79)^{\mathrm{a}}$ & $2.37(0.79)^{\mathrm{a}}$ & $2.67(0.85)^{\mathrm{b}}$ & $8.82^{* * * * *}$ \\
\hline 16. Depression & $1.75(0.84)$ & $1.88(0.89)$ & $-2.60^{* *}$ & $1.64(0.72)^{\mathrm{a}}$ & $1.72(0.78)^{\mathrm{a}}$ & $1.98(0.92)^{\mathrm{b}}$ & $8.74^{\text {***** }}$ \\
\hline
\end{tabular}

Note. Differing superscripts indicate significant differences as a function of age.

${ }^{*} p<.05 .{ }^{* * *} p<.01 .{ }^{* * *} p<.001$. 
approximation (RMSEA) $<.08$ (Little, 2013). That being said, $\chi^{2}$ is "overly sensitive to trivial sample size" (p. 108), so is likely to be significant in a sample of this size. Based on this criteria, model fit was acceptable, $\chi^{2}(83)=551.35, p<.001$, CFI $=.942$, RMSEA $=.067$. In terms of Hypothesis 1 , which dealt with direct paths from media monitoring to internalizing problems, results suggested that controlling styles of both restrictive and active monitoring were associated with higher levels of anxiety $(\beta=.14$, $p<.001$ for restrictive; $\beta=.09, p=.020$ for active) and depression $(\beta=.10, p=.003$ for restrictive; $\beta=.11, p<.001$ for active), whereas autonomy-supportive restrictive monitoring was associated with lower levels of anxiety $(\beta=-.10, p=.011)$ and depression $(\beta=-.14, p<.001)$ and autonomy-supportive active monitoring was associated with lower levels of depression ( $\beta=-.09, p=.019)$. Thus, consistent with our first hypothesis, parental media monitoring had direct effects on adolescents' internalizing problems, with controlling parenting associated with higher levels of anxiety and depression and autonomy-supportive parenting associated with lower levels of internalizing problems.

In regard to Hypothesis 2, which dealt with direct paths between media monitoring and adolescent media time, controlling restrictive monitoring was associated with higher levels of time using social media and TV, and controlling active monitoring was associated with more time media multitasking and using social media, video games, music, reading, texting, and the Internet. On the other hand, autonomy-supportive restrictive monitoring was associated with using less social media, TV, video games, music, texting, and Internet, whereas autonomy-supportive active monitoring was associated with using more social media, TV, video games, music, reading, and texting. Thus, the only type of media monitoring associated with lower levels of media use was autonomysupportive restrictive monitoring, and both types of controlling monitoring, as well as autonomy-supportive active monitoring were associated with higher levels of media use. Hypothesis 3 focused on how media was related to internalizing behavior, and we found that media multitasking was associated with higher levels of both anxiety and depression. Social media use was associated with higher levels of anxiety, and video game use was associated with higher levels of both anxiety and depression. In contrast, TV was associated with lower levels of both anxiety and depression.

In terms of controls in this model, being female was associated with more time spent with social media $(\beta=.15, p<.001)$, music $(\beta=.08, p<.001)$, and texting $(\beta=.11, p<.001)$, but less time with video games $(\beta=-.41, p<.001)$, as well as higher levels of both anxiety $(\beta=.16, p<.001)$ and depression $(\beta=.10, p=$ $.002)$. Adolescent age was associated with higher levels of media multitasking $(\beta=.26, p<.001)$, social media $(\beta=.11, p=$ $.004)$, music $(\beta=.17, p<.001)$, and texting $(\beta=.15, p<.001)$, as well as higher levels of anxiety $(\beta=.13, p=.003)$ and depression $(\beta=.12, p=.002)$. Finally, household income was associated with less time spent with music $(\beta=-.10, p=.007)$ and Internet $(\beta=-.23, p<.001)$, as well as lower levels of anxiety $(\beta=-.12, p=.003)$ and depression $(\beta=-.13, p<$ $.001)$.

Because direction of effects cannot be determined with crosssectional data, we explored an alternative model, with anxiety and depression predicting time spent with various forms of media, in turn predicting parental media monitoring. This model had lower model fit than the proposed model mentioned earlier, $\Delta \chi^{2}(35)=$ $251.31, p<.001$, providing some level of support for the hypothesized model.

\section{Indirect Effects of Parental Monitoring on Internalizing Problems}

To explore Hypothesis 4, which addressed indirect effects between media monitoring and internalizing problems via media time, we used the IND command in MPLUS. There were no significant indirect effects between autonomy-supportive restrictive monitoring and internalizing problems via any type of media use. Indeed, few indirect effects were significant, with one exception. Controlling active parental media monitoring had significant overall indirect effects with both anxiety (indirect $=.03,95 \%$ confidence interval $[.01, .20], p=.018$ ) and depression (indirect $=$ $.023,95 \%$ confidence interval $[.01, .25], p=.025$ ). Individual indirect effects suggested that the positive link between controlling active media monitoring and both anxiety and depression were explained by increases in media multitasking (indirect $=.02, p=$ .013 ; indirect $=.015, p=.027$ ) and video game use (indirect $=$ $.01, p=.040$; indirect $=.014, p=.058$; depression effect is marginally significant). Thus, Hypothesis 4 was largely unsupported, as media use did not explain the links between parental media monitoring and internalizing problems, except in the case of poorly executed parental media monitoring, specifically, active monitoring done in a controlling manner.

\section{Multiple Group Model by Adolescent Age and Sex}

To explore Research Question 1 regarding whether associations in the current model differed as a function of adolescents' age, we performed multiple group analyses with age categorized as early (age 10-12), middle (13-15), and late $(16+)$ adolescents. Given that the majority of paths that could not be constrained across age were between controls and media or mental health, we felt confident saying that the current model functions quite similarly across early, middle, and late adolescents. See online supplemental materials for analyses as a function of adolescent age.

To explore whether associations in the current model differed as a function of adolescents' sex ( $0=$ boys, $1=$ girls $)$, we performed multiple group analyses; unconstrained model: $\chi^{2}(172)=662.68$, $p<.001, \mathrm{CFI}=.934, \mathrm{RMSEA}=.049$. Model comparison using $\chi^{2}$ change suggested that constraining all paths to be equal as a function of adolescent sex resulted in a significant decrease in model fit, $\Delta \chi^{2}(92)=435.64, p<.001$. Each structural path was explored to determine which paths could be constrained across sex, and which should be left free to vary. This analysis represented 68 paths (including controls), and follow-up analyses suggested that five paths could not be constrained to be equal, so these five paths were left free to vary, whereas all other paths were constrained to be equal, $\chi^{2}(213)=702.55, p<.001, \mathrm{CFI}=.934$, RMSEA $=$ .044. The paths that could not be constrained to be equal were those from media use to internalizing problems (see Figure 1). Namely, frequency of TV use $(\beta=-.12, p=.012)$ and texting (marginally; $\beta=-.11, p=.060$ ) were negatively associated with anxiety for boys, but not for girls $(\beta=-.06, p=.125 ; \beta=-.02$, $p=.711)$, whereas video game use was positively associated with 


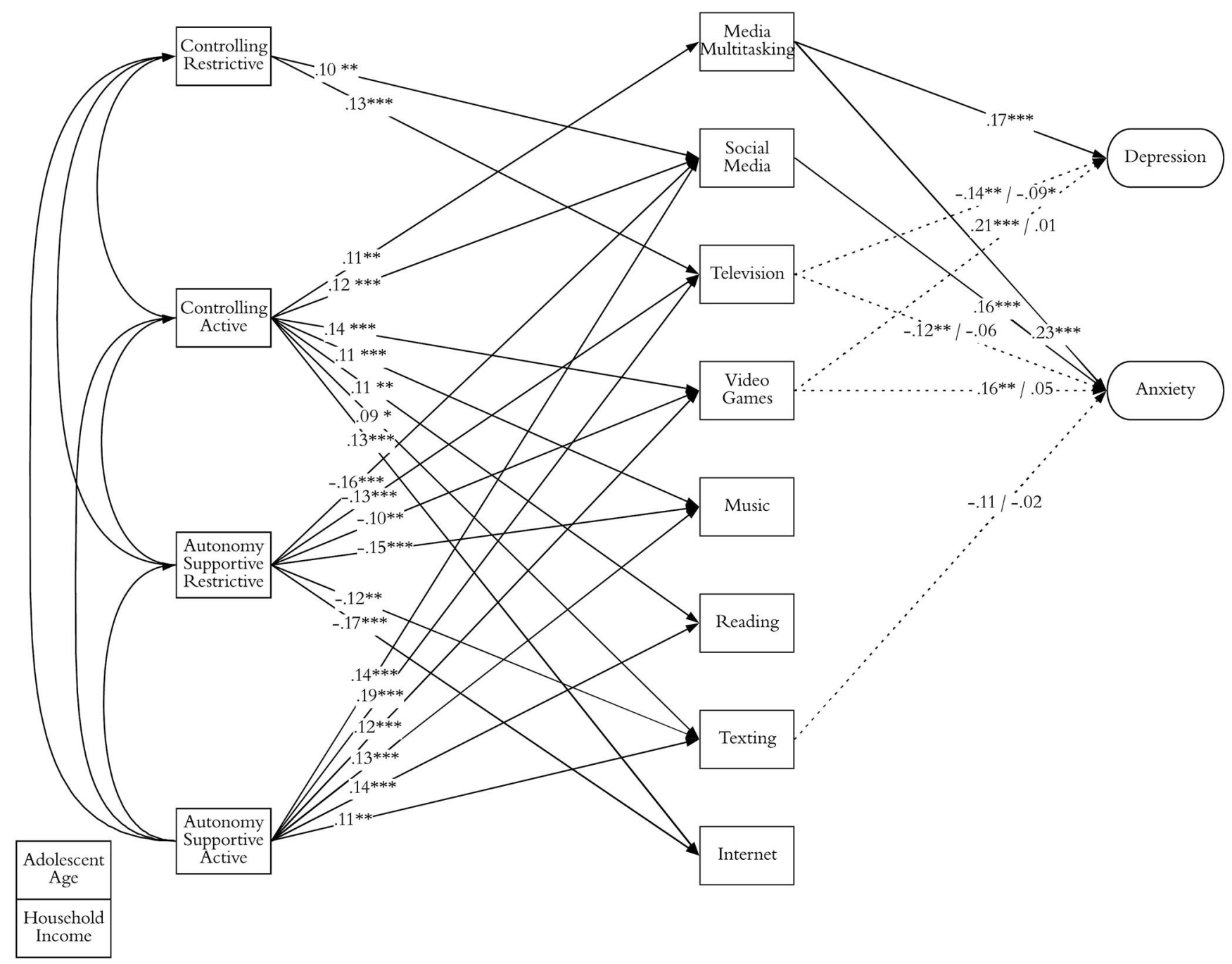

Figure 1. Associations between parental media monitoring, media use, and internalizing problems. Only significant standardized paths are shown; dashed lines indicate paths that were left free to vary by adolescent sex. Values for males are before the slash, females are after. Direct paths from media monitoring to internalizing problems are not included in figure, but are in the text. Error terms and covariances on endogenous variables are omitted for parsimony. ${ }^{*} p<.05 .{ }^{* *} p<.01{ }^{* * * *} p<.001$.

anxiety for boys $(\beta=.16, p=.002)$ but not for girls $(\beta=.05, p=$ .296). Frequency of TV use was also more strongly negatively associated with depression for boys $(\beta=-.14, p=.002)$ than for girls $(\beta=-.09, p=.029)$, and video game use was positively associated with depression for boys $(\beta=.21, p<.001)$ but not girls $(\beta=.01, p=.745)$.

\section{Discussion}

The present study explored the cross-sectional relations between parental media monitoring, adolescent media multitasking and media use, and adolescents' internalizing behaviors. One of the most important findings was that parental controlling restrictive, controlling active, and autonomy-supportive active media monitoring were related to adolescents' increased media use. Previous researchers have shown that restrictive parental media monitoring is related to increased adolescent media use (Gentile et al., 2014), and researchers have argued that such restrictive rules make limited media a "forbidden fruit" that encourages more adolescent media use and increased media hiding from parents (Bijvank, Konijn, Bushman, \& Roelofsma, 2009; Bushman, 2006; Bushman $\&$ Cantor, 2003). However, these previous studies have failed to take into consideration controlling versus autonomy-supportive styles of parental media monitoring. In the current study, the only parental monitoring style that was associated with less media time for adolescents was autonomy-supportive restrictive monitoring. Adolescents, with their expanded cognitive capacities and increased autonomy, still benefit from rules, regulations, and guidance by parents. Perhaps parents who can balance the need for regulations regarding the media with the need to respect, support, and encourage the autonomy of their adolescents create a family 
environment and parent-child relationship that fosters clear and open communication, and support for and compliance with family rules, including media use.

It is also of note that both controlling approaches to media monitoring were directly associated with higher levels of internalizing problems, whereas autonomy-supportive approaches were associated with lower levels of internalizing problems. Previous research has shown that controlling parenting styles, in general, are related to internalizing behavior (Soenens, Vansteenkiste, \& Van Petegem, 2015; Williams et al., 2009), and the current study adds to this by suggesting that controlling parenting styles regarding media use are also directly related to internalizing behaviors during adolescence. Controlling parenting styles may lead adolescents to spend more time with the media as a way to escape and express their own identity and culture (Arnett, 2004), which may place these teens at increased risk for excessive media time and increased internalizing problems. Likewise, these teens may not have an open and supportive communication pattern with their parents; therefore, they may be more likely to internalize problems instead of reaching outward for support and help from parents.

\section{Links Between Media Use and Adolescents' Internalizing Symptoms}

Another important finding of the current study was that media multitasking was related to higher levels of internalizing problems in adolescents. Previous research examining young adolescent females' media multitasking found that media multitasking was related to poorer social relationships and interactions, online and in real life (Pea et al., 2012), which may help explain the relations between media multitasking and internalizing behaviors in the current study. However, other longitudinal, lab-based assessments of media multitasking have found that young adults multitask to fulfill an emotional need, even though media multitasking impedes cognitive performance (Wang \& Tchernev, 2012). This study would suggest that the relations between media multitasking and adolescent internalizing behaviors may be explained by adolescents' motivations and reasons for media multitasking in the first place. The cross-sectional nature of the current study does not allow for the examination of direction of effects or the disentangling of these two explanations. However, it is likely a bidirectional relationship with adolescents who are experiencing internalizing symptoms being more likely to media multitask to meet an emotional need, while at the same time media multitasking increases social isolation and risk for internalizing symptoms.

In line with the media practice model, media multitasking may lead to interacting with media with more negative messages, and teens may apply these messages more to their own lives (Marino et al., 2016; Rubin, 1994; Spada et al., 2008). Displacement and diminished cognitive control and resources theories regarding media multitasking have argued that media multitasking displaces other activities that may be related to positive behavioral outcomes and leave less cognitive resources for meaningful processing, comprehension, and application of social and media-related messages (van der Schuur et al., 2015). This displacement of positive social interactions and protective factors due to spending so much time with the media and decreased cognitive resources being allocated to critical evaluation of the media may place teens at increased risk for the development and exacerbation of internalizing symptoms as a result of media use.

Also of importance, the current study found that social media and video games were associated with internalizing symptoms. Previous researchers have shown mixed relations between social media use and internalizing symptoms (O'Keeffe \& ClarkePearson, 2011), which is likely due to the varying content of social media and individuals' varying application of this content to their individual lives. Frequently people portray their best selves, only the happiest and perfect moments on social media (Perloff, 2014). As a result, teens may compare their worst moments to their peers' best moments, increasing feelings of depression, anxiety, social exclusion, and hopelessness. In fact, young adults who are envious of other's social media posts are more likely to show depressive symptoms than those who are not envious (Tandoc et al., 2015). Thus, the current findings are consistent with past research and suggest the need to consider motivation for the selection of social media use, as well as social media content and how teens are applying this content to their daily lives. In terms of video games, teens (especially boys) may use video games as an immersive way to escape their own lives to enter a world of fantasy (Ryan, Rigby, $\&$ Przybylski, 2006). Teens at risk for internalizing symptoms may be more likely to select video games as a means of escape, as suggested by the media practice model. However, the online communities of video games can be hostile (Yang, 2012), and the majority of the top selling video games are violent (Dill, Gentile, Richter, \& Dill, 2005). Exposure to this content (rather than video games themselves) may be the salient mechanism promoting adolescent internalizing symptoms, so future research should consider this possibility. Alternatively, if displacement from social interaction is the mechanism in this regard, it is possible that video games played in isolation are associated with internalizing symptoms, whereas those played with friends or family are not, which should be explored in future research.

Interestingly, the current study did not find any associations between listening to music, reading, texting, or Internet use (excluding social media) and adolescents' internalizing symptoms. This supports the assertion that not all media is created equal, has equal effects, or should be treated the same in research. It is important for future researchers to continue to take a more nuanced view of adolescent media use by including multiple media types, media content, and how these differing types of media and their associated content are related to adolescent behavioral outcomes.

\section{The Moderating Role of Adolescent Sex}

The current study found minimal differences as a function of adolescent sex and age in regard to the relations between parental media monitoring, media use, or internalizing behaviors. Overall, this suggests that the model in the current study functioned similarly across adolescents, with a few exceptions. In line with past research, girls spent more time using social media (Nesi \& Prinstein, 2015) and texting (Ogletree, Fancher, \& Gill, 2014) than did boys, and boys spent more time playing video games (Greenberg, Sherry, Lachlan, Lucas, \& Holmstrom, 2010). In line with the media practice model, adolescent females and males may differ in their selection and interaction with the media and as a result they may display differences in application and media-related outcomes. For example, researchers have argued that adolescent fe- 
males' media diets may be due to their greater need for social engagement and relationship formation, which may be biologically or culturally driven. Social media and texting may lead females to content that promotes social comparisons and envy, which is related to increased internalizing symptomology. Likewise, girls are known to be at increased biological and social risk for earlier onset and increased levels of internalizing symptoms (Altemus et al., 2014; Breslau et al., 2017), further exacerbating the effects of social media use and social comparison.

In addition to mean differences, moderation analyses in the current study found that links between media and internalizing problems were different for boys and girls in some cases. It is of note that positive associations between media multitasking and depression and anxiety and social media and anxiety did not differ as a function of adolescent sex, but all other paths did. Namely, video games were positively associated with depression and anxiety for boys, but not girls, and TV and texting were negatively associated with depression and anxiety (only anxiety for texting) for boys, but not girls. These findings suggest that not only do boys and girls use different media at different levels, but also that media might differentially impact boys and girls, with special focus on the negative relations between video games and internalizing problems for boys. These findings also highlight some of the positive roles that $\mathrm{TV}$ and texting might play, especially in the lives of boys. It is possible that these types of media are helping boys to engage in social relationships that protect against internalizing symptoms. Furthermore, there may be biological and social factors related to the boys who select TV and texting as a type of media versus video games that are underlying these relations. Future research is needed to more fully understand these differences, and it is important that selection motivations, interaction characteristics, and application mechanisms are taken into consideration when examining the relations between adolescent media use and behavioral outcomes.

\section{Limitations and Conclusions}

Although the current study adds important information regarding parental media monitoring, adolescent media use, and adolescent internalizing behaviors to the current literature, it is not without limitations. The current study was cross-sectional and cannot speak to direction of effects. Although it is of note that both theoretical (Steele \& Brown, 1995) and empirical (Bickham et al., 2015; Houghton et al., 2018; Nesi et al., 2017) research supports the direction of effects postulated in the current study, bidirectional relations are also likely. Thus, future researchers should examine these variables longitudinally to disentangle the direction of effects and determine whether these relations are short term or long term in nature. It is also important to note that the effects sizes of significant paths in the current study were small, so although significant, the links between parenting and media use and between media use and internalizing problems should not be overstated. It is also of note that indirect effects were generally not significant in the current study. Thus, we can conclude that parental monitoring is associated with internalizing symptoms and that media is associated with internalizing symptoms, but we learned little about the mechanisms that might explain why parental media monitoring is associated with lower or higher levels of internalizing symptoms. Future research should explore additional media- tors such as critical thinking skills, relationship quality, and media content. The current study also relied on self-report measures of media use and parental media monitoring, which only present one perspective of this dynamic process. Future researchers should employ observational methods and use multiple reporters to study these relationships.

Even considering the aforementioned limitations, the current study adds important insights into the role of parental media monitoring style and adolescent media use as they relate to adolescents' internalizing symptoms. Most importantly, this study highlights the need to consider parental media monitoring in context of the style in which it occurs. Namely, only autonomysupportive restrictive media monitoring was associated with lower levels of media use, suggesting that teens of all ages can benefit from media rules and limits if they are delivered with the intent to maximize autonomy. Findings also highlighted links between media multitasking and internalizing problems, and suggested that social media and video games (the latter for boys only) were also linked to higher levels of internalizing symptoms. These findings suggest utility in parents and educators being more aware of media multitasking, video game use, and social media use as potential risk factors for youth. Findings also suggest that future research should consider different types of media because although some platforms may be more detrimental, others may be protective (e.g., texting and TV for boys). Future research should also expand beyond media time and focus on motivations and implications for why adolescents are selecting media, how they are interacting with media, and how they are applying the messages contained within this media to their everyday lives.

\section{References}

Altemus, M., Sarvaiya, N., \& Neill Epperson, C. (2014). Sex differences in anxiety and depression clinical perspectives. Frontiers in Neuroendocrinology, 35, 320-330. http://dx.doi.org/10.1016/j.yfrne.2014.05.004

Alzahabi, R., \& Becker, M. W. (2013). The association between media multitasking, task-switching, and dual-task performance. Journal of Experimental Psychology: Human Perception and Performance, 39, 1485-1495. http://dx.doi.org/10.1037/a0031208

Anderson, M., \& Jiang, J. (2018). Teens, social media, and technology 2018. Washington, DC: Pew Institute. Retrieved from http:// publicservicesalliance.org/wp-content/uploads/2018/06/Teens-SocialMedia-Technology-2018-PEW.pdf

Arnett, J. J. (2004). Emerging adulthood: The winding road from the late teens through the twenties. New York, NY: Oxford University Press.

Avenevoli, S., \& Steinberg, L. (2001). The continuity of depression across the adolescent transition. In H. Reese \& R. Kail (Eds.), Advances in child development and behavior (Vol. 28, pp. 139-173). New York, NY: Academic Press.

Barcaccia, B., Balestrini, V., Saliani, A. M., Baiocco, R., Mancini, F., \& Schneider, B. H. (2017). Dysfunctional eating behaviors, anxiety, and depression in Italian boys and girls: The role of mass media. Revista Brasileira de Psiquiatria, 40, 72-77. http://dx.doi.org/10.1590/15164446-2016-2200

Baumgartner, S. E., Weeda, W. D., van der Heijden, L. L., \& Huizinga, M. (2014). The relationship between media multitasking and executive function in early adolescents. The Journal of Early Adolescence, 34, 1120-1144. http://dx.doi.org/10.1177/0272431614523133

Becker, M. W., Alzahabi, R., \& Hopwood, C. J. (2013). Media multitasking is associated with symptoms of depression and social anxiety. Cyberpsychology, Behavior, and Social Networking, 16, 132-135. http:// dx.doi.org/10.1089/cyber.2012.0291 
Bickham, D. S., Hswen, Y., \& Rich, M. (2015). Media use and depression: Exposure, household rules, and symptoms among young adolescents in the USA. International Journal of Public Health, 60, 147-155. http:// dx.doi.org/10.1007/s00038-014-0647-6

Bijvank, M. N., Konijn, E. A., Bushman, B. J., \& Roelofsma, P. H. M. P. (2009). Age and violent-content labels make video games forbidden fruits for youth. Pediatrics, 123, 870-876. http://dx.doi.org/10.1542/ peds.2008-0601

Brenhouse, H. C., Sonntag, K. C., \& Andersen, S. L. (2008). Transient D1 dopamine receptor expression on prefrontal cortex projection neurons: Relationship to enhanced motivational salience of drug cues in adolescence. The Journal of Neuroscience, 28, 2375-2382. http://dx.doi.org/ 10.1523/JNEUROSCI.5064-07.2008

Breslau, J., Gilman, S. E., Stein, B. D., Ruder, T., Gmelin, T., \& Miller, E. (2017). Sex differences in recent first-onset depression in an epidemiological sample of adolescents. Translational Psychiatry, 7, e1139. http:// dx.doi.org/10.1038/tp.2017.105

Bushman, B. J. (2006). Effects of warning and information labels on attraction to television violence in viewers of different ages. Journal of Applied Social Psychology, 36, 2073-2078. http://dx.doi.org/10.1111/j .0021-9029.2006.00094.x

Bushman, B. J., \& Cantor, J. (2003). Media ratings for violence and sex. Implications for policymakers and parents. American Psychologist, 58, 130-141. http://dx.doi.org/10.1037/0003-066X.58.2.130

Collier, K. M., Coyne, S. M., Rasmussen, E. E., Hawkins, A. J., PadillaWalker, L. M., Erickson, S. E., \& Memmott-Elison, M. K. (2016). Does parental mediation of media influence child outcomes? A meta-analysis on media time, aggression, substance use, and sexual behavior. Developmental Psychology, 52, 798-812. http://dx.doi.org/10.1037/ dev0000108

Coyne, S. M., Padilla-Walker, L. M., \& Holmgren, H. G. (2018). A six-year longitudinal study of texting trajectories during adolescence. Child Development, 89, 58-65. http://dx.doi.org/10.1111/cdev.12823

Coyne, S. M., Padilla-Walker, L. M., Holmgren, H. G., \& Stockdale, L. A. (2018). Instagrowth: A longitudinal growth mixture model of social media time use across adolescence. Journal of Research on Adolescence. Advance online publication. http://dx.doi.org/10.1111/jora.12424

Coyne, S. M., Padilla-Walker, L. M., Stockdale, L., \& Day, R. D. (2011). Game on . . . girls: Associations between co-playing video games and adolescent behavioral and family outcomes. Journal of Adolescent Health, 49, 160-165. http://dx.doi.org/10.1016/j.jadohealth.2010.11 .249

Cumming, R. G. (1990). Is probability sampling always better? A comparison of results from a quota and a probability sample survey. Community Health Studies, 14, 132-137. http://dx.doi.org/10.1111/j.17536405.1990.tb00033.x

Deci, E. L., \& Ryan, R. M. (2012). Self-determination theory. In P. A. M. Van Lange, A. W. Kruglanski, \& E. T. Higgins (Eds.), Handbook of theories of social psychology (pp. 416-437). Thousand Oaks, CA: Sage. http://dx.doi.org/10.4135/9781446249215.n21

Dill, K. E., Gentile, D. A., Richter, W. A., \& Dill, J. C. (2005). Violence, sex, race and age in popular video games: A content analysis. In E. Cole \& J. H. Daniel (Eds.), Psychology of women book series. Featuring females: Feminist analyses of the media (pp. 115-130). Washington, DC: American Psychological Association. http://dx.doi.org/10.1037/ 11213-008

Do, Y. K., Shin, E., Bautista, M. A., \& Foo, K. (2013). The associations between self-reported sleep duration and adolescent health outcomes: What is the role of time spent on Internet use? Sleep Medicine, 14, 195-200. http://dx.doi.org/10.1016/j.sleep.2012.09.004

Domingues-Montanari, S. (2017). Clinical and psychological effects of excessive screen time on children. Journal of Paediatrics and Child Health, 53, 333-338. http://dx.doi.org/10.1111/jpc.13462
Eschenbeck, H., Schmid, S., Schröder, I., Wasserfall, N., \& Kohlmann, C.-W. (2018). Development of coping strategies from childhood to adolescence: Cross-sectional and longitudinal trends. European Journal of Health Psychology, 25, 18-30. http://dx.doi.org/10.1027/2512-8442/ a000005

Fardouly, J., Magson, N. R., Johnco, C. J., Oar, E. L., \& Rapee, R. M. (2018). Parental control of the time preadolescents spend on social media: Links with preadolescents' social media appearance comparisons and mental health. Journal of Youth and Adolescence, 47, 1456-1468. http://dx.doi.org/10.1007/s10964-018-0870-1

Faulstich, M. E., Carey, M. P., Ruggiero, L., Enyart, P., \& Gresham, F. (1986). Assessment of depression in childhood and adolescence: An evaluation of the Center for Epidemiological Studies Depression Scale for children (CES-DC). The American Journal of Psychiatry, 143, 1024-1027. http://dx.doi.org/10.1176/ajp.143.8.1024

Fikkers, K. M., Piotrowski, J. T., \& Valkenburg, P. M. (2017). A matter of style? Exploring the effects of parental mediation styles on early adolescents' media violence exposure and aggression. Computers in Human Behavior, 70, 407-415. http://dx.doi.org/10.1016/j.chb.2017.01.029

Gentile, D. A., Choo, H., Liau, A., Sim, T., Li, D., Fung, D., \& Khoo, A. (2011). Pathological video game use among youths: A two-year longitudinal study. Pediatrics, 127, e319-e329. http://dx.doi.org/10.1542/ peds.2010-1353

Gentile, D. A., Nathanson, A. I., Rasmussen, E. E., Reimer, R. A., \& Walsh, D. A. (2012). Do you see what I see? Parent and child reports of parental monitoring of media. Family Relations: An Interdisciplinary Journal of Applied Family Studies, 61, 470-487. http://dx.doi.org/10 $.1111 / \mathrm{j} .1741-3729.2012 .00709 . x$

Gentile, D. A., Reimer, R. A., Nathanson, A. I., Walsh, D. A., \& Eisenmann, J. C. (2014). Protective effects of parental monitoring of children's media use: A prospective study. Journal of the American Medical Association Pediatrics, 168, 479-484. http://dx.doi.org/10.1001/ jamapediatrics.2014.146

Graber, J., \& Sontag, L. (2009). Internalizing problems during adolescence. In R. Lerner \& L. Steinberg (Eds.), Handbook of adolescent psychology (3rd ed., Vol. 1, pp. 642-682). New York, NY: Wiley. http://dx.doi.org/ 10.1002/9780470479193.adlpsy001020

Greenberg, B. S., Sherry, J., Lachlan, K., Lucas, K., \& Holmstrom, A. (2010). Orientations to video games among gender and age groups. Simulation and Gaming, 41, 238-259. http://dx.doi.org/10.1177/ 1046878108319930

Hayward, C., \& Sanborn, K. (2002). Puberty and the emergence of gender differences in psychopathology. Journal of Adolescent Health, 30, 49 58. http://dx.doi.org/10.1016/S1054-139X(02)00336-1

Holtz, P., \& Appel, M. (2011). Internet use and video gaming predict problem behavior in early adolescence. Journal of Adolescence, 34, 49-58. http://dx.doi.org/10.1016/j.adolescence.2010.02.004

Houghton, S., Lawrence, D., Hunter, S. C., Rosenberg, M., Zadow, C., Wood, L., \& Shilton, T. (2018). Reciprocal relationships between trajectories of depressive symptoms and screen media use during adolescence. Journal of Youth and Adolescence, 47, 2453-2467. http://dx.doi .org/10.1007/s10964-018-0901-y

Hussong, A. M., Jones, D. J., Stein, G. L., Baucom, D. H., \& Boeding, S. (2011). An internalizing pathway to alcohol use and disorder. Psychology of Addictive Behaviors, 25, 390-404. http://dx.doi.org/10.1037/ a0024519

Jelenchick, L. A., Eickhoff, J. C., \& Moreno, M. A. (2013). "Facebook depression?" Social networking site use and depression in older adolescents. Journal of Adolescent Health, 52, 128-130. http://dx.doi.org/10 .1016/j.jadohealth.2012.05.008

Kelley, A. E., Schochet, T., \& Landry, C. F. (2004). Risk taking and novelty seeking in adolescence: Introduction to part I. Annals of the New York Academy of Sciences, 1021, 27-32. http://dx.doi.org/10.1196/ annals. 1308.003 
Lai, C. M., Mak, K. K., Watanabe, H., Jeong, J., Kim, D., Bahar, N., . . . Cheng, C. (2015). The mediating role of Internet addiction in depression, social anxiety, and psychosocial well-being among adolescents in six Asian countries: A structural equation modelling approach. Public Health, 129, 1224-1236. http://dx.doi.org/10.1016/j.puhe.2015.07.031

Little, T. D. (2013). Longitudinal structural equation modeling. New York, NY: Guilford.

Maras, D., Flament, M. F., Murray, M., Buchholz, A., Henderson, K. A., Obeid, N., \& Goldfield, G. S. (2015). Screen time is associated with depression and anxiety in Canadian youth. Preventive Medicine, 73, 133-138. http://dx.doi.org/10.1016/j.ypmed.2015.01.029

Marino, C., Vieno, A., Moss, A. C., Caselli, G., Nikčević, A. V., \& Spada, M. M. (2016). Personality, motives and metacognitions as predictors of problematic Facebook use in university students. Personality and Individual Differences, 101, 70-77. http://dx.doi.org/10.1016/j.paid.2016.05 .053

Nathanson, A. I. (1999). Identifying and explaining the relationship between parental mediation and children's aggression. Communication Research, 26, 124-143. http://dx.doi.org/10.1177/009365099026002002

Nathanson, A. I., \& Cantor, J. (2000). Reducing the aggression-promoting effect of violent cartoons by increasing children's fictional involvement with the victim: A study of active mediation. Journal of Broadcasting and Electronic Media, 44, 125-142. http://dx.doi.org/10.1207/ s15506878jobem4401_9

National Institute of Mental Health. (2016). Major depression. Rockville, MD: Author. Retrieved from https://www.nimh.nih.gov/health/ statistics/major-depression.shtml

Natsuaki, M. N., Klimes-Dougan, B., Ge, X., Shirtcliff, E. A., Hastings, P. D., \& Zahn-Waxler, C. (2009). Early pubertal maturation and internalizing problems in adolescence: Sex differences in the role of cortisol reactivity to interpersonal stress. Journal of Clinical Child and Adolescent Psychology, 38, 513-524. http://dx.doi.org/10.1080/ 15374410902976320

Nesi, J., Miller, A. B., \& Prinstein, M. J. (2017). Adolescents' depressive symptoms and subsequent technology-based interpersonal behaviors: A multi-wave study. Journal of Applied Developmental Psychology, 51, 12-19. http://dx.doi.org/10.1016/j.appdev.2017.02.002

Nesi, J., \& Prinstein, M. J. (2015). Using social media for social comparison and feedback-seeking: Gender and popularity moderate associations with depressive symptoms. Journal of Abnormal Child Psychology, 43, 1427-1438. http://dx.doi.org/10.1007/s10802-015-0020-0

Ogletree, S. M., Fancher, J., \& Gill, S. (2014). Gender and texting: Masculinity, femininity, and gender role ideology. Computers in Human Behavior, 37, 49-55. http://dx.doi.org/10.1016/j.chb.2014.04.021

O'Keeffe, G. S., \& Clarke-Pearson, K. (2011). The impact of social media on children, adolescents, and families. Pediatrics, 127, 800-804. http:// dx.doi.org/10.1542/peds.2011-0054

Ophir, E., Nass, C., \& Wagner, A. D. (2009). Cognitive control in media multitaskers. Proceedings of the National Academy of Sciences of the United States of America, 106, 15583-15587. http://dx.doi.org/10.1073/ pnas.0903620106

Padilla-Walker, L. M., Coyne, S. M., \& Collier, K. M. (2016). Longitudinal relations between parental media monitoring and adolescent aggression, prosocial behavior, and externalizing problems. Journal of Adolescence, 46, 86-97. http://dx.doi.org/10.1016/j.adolescence.2015 .11 .002

Padilla-Walker, L. M., Coyne, S. M., Kroff, S. L., \& Memmott-Elison, M. K. (2018). The protective role of parental media monitoring style from early to late adolescence. Journal of Youth and Adolescence, 47, 445-459. http://dx.doi.org/10.1007/s10964-017-0722-4

Palmer, C. A., Oosterhoff, B., Bower, J. L., Kaplow, J. B., \& Alfano, C. A. (2018). Associations among adolescent sleep problems, emotion regulation, and affective disorders: Findings from a nationally representative sample. Journal of Psychiatric Research, 96, 1-8. http://dx.doi.org/10 .1016/j.jpsychires.2017.09.015

Pardini, D., Lochman, J., \& Wells, K. (2004). Negative emotions and alcohol use initiation in high-risk boys: The moderating effect of good inhibitory control. Journal of Abnormal Child Psychology, 32, 505-518. http://dx.doi.org/10.1023/B:JACP.0000037780.22849.23

Pea, R., Nass, C., Meheula, L., Rance, M., Kumar, A., Bamford, H., . . . Zhou, M. (2012). Media use, face-to-face communication, media multitasking, and social well-being among 8- to 12-year-old girls. Developmental Psychology, 48, 327-336. http://dx.doi.org/10.1037/a0027030

Perloff, R. M. (2014). Social media effects on young women's body image concerns: Theoretical perspectives and an agenda for research. Sex Roles, 71, 363-377. http://dx.doi.org/10.1007/s11199-014-0384-6

Pew Research Center. (2016). Evaluation online nonprobability surveys. Retrieved from http://www.pewresearch.org.erl.lib.byu.edu/files/2016/ 04/Nonprobability-report-May-2016-FINAL.pdf

Primack, B. A., Shensa, A., Escobar-Viera, C. G., Barrett, E. L., Sidani, J. E., Colditz, J. B., \& James, A. E. (2017). Use of multiple social media platforms and symptoms of depression and anxiety: A nationallyrepresentative study among U.S. young adults. Computers in Human Behavior, 69, 1-9. http://dx.doi.org/10.1016/j.chb.2016.11.013

Reinecke, L., Aufenanger, S., Beutel, M. E., Dreier, M., Quiring, O., Stark, B., ... Müller, K. W. (2017). Digital stress over the life span: The effects of communication load and internet multitasking on perceived stress and psychological health impairments in a German probability sample. Media Psychology, 20, 90-115. http://dx.doi.org/10.1080/15213269.2015 .1121832

Rideout, V. (2016). Measuring time spent with media: The common sense census of media use by U.S. 8- to 18-year-olds. Journal of Children and Media, 10, 138-144. http://dx.doi.org/10.1080/17482798.2016.1129808

Rubin, A. (1994). Media uses and effects: A uses-and-gratifications perspective. In J. Bryant \& D. Zillmann (Eds.), Media effects: Advances in theory and research (pp. 437-461). Hillsdale, NJ: Erlbaum.

Ryan, R. M., Rigby, C. S., \& Przybylski, A. (2006). The motivational pull of video games: A self-determination theory approach. Motivation and Emotion, 30, 344-363. http://dx.doi.org/10.1007/s11031-006-9051-8

Soenens, B., Luyckx, K., Vansteenkiste, M., Duriez, B., \& Goossens, L. (2008). Clarifying the link between parental psychological control and adolescents' depressive symptoms: Reciprocal versus unidirectional models. Merrill-Palmer Quarterly, 54, 411-444. http://dx.doi.org/10 $.1353 / \mathrm{mpq} \cdot 0.0005$

Soenens, B., Vansteenkiste, M., \& Beyers, W. (2019). Parenting adolescents. In M. H. Bornstein (Ed.), Handbook of parenting: Children and parenting (3rd ed., Vol. 1, pp. 101-167). Abingdon, United Kingdom: Routledge. http://dx.doi.org/10.4324/9780429440847-4

Soenens, B., Vansteenkiste, M., \& Van Petegem, S. (2015). Let us not throw out the baby with the bathwater: Applying the principle of universalism without uniformity to autonomy-supportive and controlling parenting. Child Development Perspectives, 9, 44-49. http://dx.doi.org/ 10.1111/cdep. 12103

Spada, M. M., Langston, B., Nikčević, A. V., \& Moneta, G. B. (2008). The role of metacognitions in problematic Internet use. Computers in Human Behavior, 24, 2325-2335. http://dx.doi.org/10.1016/j.chb.2007.12.002

Spence, S. H. (1998). A measure of anxiety symptoms among children. Behaviour Research and Therapy, 36, 545-566. http://dx.doi.org/10 .1016/S0005-7967(98)00034-5

Steele, J. R., \& Brown, J. D. (1995). Adolescent room culture: Studying media in the context of everyday life. Journal of Youth and Adolescence, 24, 551-576. http://dx.doi.org/10.1007/BF01537056

Stockdale, L. A., Coyne, S. M., \& Padilla-Walker, L. M. (2018). Parent and child technoference and socioemotional behavioral outcomes: A nationally representative study of 10-to 20-year-old adolescents. Computers in Human Behavior, 88, 219-226. http://dx.doi.org/10.1016/j.chb.2018.06 .034 
Tandoc, E. C., Jr., Ferrucci, P., \& Duffy, M. (2015). Facebook use, envy, and depression among college students: Is facebooking depressing? Computers in Human Behavior, 43, 139-146. http://dx.doi.org/10.1016/ j.chb.2014.10.053

Twenge, J. M., Joiner, T. E., Rogers, M. L., \& Martin, G. N. (2018). Increases in depressive symptoms, suicide-related outcomes, and suicide rates among U.S. adolescents after 2010 and links to increased new media screen time. Clinical Psychological Science, 6, 3-17. http://dx .doi.org/10.1177/2167702617723376

Valkenburg, P. M., Piotrowski, J. T., Hermanns, J., \& de Leeuw, R. (2013). Developing and validating the perceived parental media mediation scale: A self-determination perspective. Human Communication Research, 39, 445-469. http://dx.doi.org/10.1111/hcre.12010

van der Schuur, W. A., Baumgartner, S. E., Sumter, S. R., \& Valkenburg, P. M. (2015). The consequences of media multitasking for youth: A review. Computers in Human Behavior, 53, 204-215. http://dx.doi.org/ 10.1016/j.chb.2015.06.035

Wang, Z., \& Tchernev, J. M. (2012). The "myth" of media multitasking: Reciprocal dynamics of media multitasking, personal needs, and gratifications. Journal of Communication, 62, 493-513. http://dx.doi.org/10 $.1111 / \mathrm{j} .1460-2466.2012 .01641 . x$

Weinberger, A. H., Gbedemah, M., Martinez, A. M., Nash, D., Galea, S., \& Goodwin, R. D. (2018). Trends in depression prevalence in the USA from 2005 to 2015: Widening disparities in vulnerable groups. Psychological Medicine, 48, 1308-1315. http://dx.doi.org/10.1017/ S0033291717002781

Weinstein, S. M., Mermelstein, R. J., Hankin, B. L., Hedeker, D., \& Flay, B. R. (2007). Longitudinal patterns of daily affect and global mood during adolescence. Journal of Research on Adolescence, 17, 587-600. http://dx.doi.org/10.1111/j.1532-7795.2007.00536.x

Werner, L. L. A. A., der Graaff, J. V., Meeus, W. H. J., \& Branje, S. J. T. (2016). Depressive symptoms in adolescence: Longitudinal links with maternal empathy and psychological control. Journal of Abnormal Child Psychology, 44, 1121-1132. http://dx.doi.org/10.1007/s10802-0150106-8

Williams, L. R., Degnan, K. A., Perez-Edgar, K. E., Henderson, H. A., Rubin, K. H., Pine, D. S., . . . Fox, N. A. (2009). Impact of behavioral inhibition and parenting style on internalizing and externalizing problems from early childhood through adolescence. Journal of Abnormal Child Psychology, 37, 1063-1075. http://dx.doi.org/10.1007/s10802009-9331-3

Woods, H. C., \& Scott, H. (2016). \#Sleepyteens: Social media use in adolescence is associated with poor sleep quality, anxiety, depression and low self-esteem. Journal of Adolescence, 51, 41-49. http://dx.doi .org/10.1016/j.adolescence.2016.05.008

World Health Organization. (2018). Depression fact sheet. Geneva, Switzerland: Author. Retrieved from http://www.who.int/en/news-room/factsheets/detail/depression

Yang, S. C. (2012). Paths to bullying in online gaming: The effects of gender, preference for playing violent games, hostility, and aggressive behavior on bullying. Journal of Educational Computing Research, 47, 235-249. http://dx.doi.org/10.2190/EC.47.3.a

Received January 18, 2019

Revision received July 30, 2019

Accepted July 31, 2019 